\title{
A Thermal Model of the Building for the Design of Temperature Control Algorithms
}

\section{Introduction}

\subsection{Motivation}

The use of mathematical modeling and numerical simulation of heat dynamics in a building is an efficient and practical method to reduce energy consumption and to improve thermal comfort. A model can serve as a useful tool in selecting insulating materials, size and heat output of radiators, parameters of ventilation and heating systems. A model can also help in selecting optimal values of the control parameters in pursuit of energy efficient utilization.

The aim of this paper is to produce the simplest possible model of a building that incorporates the major features of heat transfer dynamics. In addition, it is recommended to have a model which parameters can be estimated already at the design phase of a building. This allows for making the right decisions when it comes to selecting building technology, devices, and installations. The last but not least thing is to have a model in a form that allows for the efficient design of the control algorithms.

\subsection{Related work}

The modeling approach examined in this paper is based on the heat conduction equation published by Joseph Fourier in 1822 [3]. The mathematical theory of heat conduction has been the topic of hundreds of publication, numerous monographs, and several comprehensive textbooks, such as $[6,7,11,16]$. A systematic review of the historical evolution of mathematical models applied in the development of building technology can be found in $[9,10]$. The review with the references therein provides an insight into various forms of modeling approaches including physical modeling, neural networks, expert systems, fuzzy logic, and genetic models.

Many researchers have applied and extended the heat conduction equation to obtain models for detailed analysis of building thermal phenomenon. Lu [8] has described the thermal model of a building by nonlinear partial differential equations that have been solved by 
the finite element method. In the paper [1] a model of heat dynamics in a test building has been formulated as a system of stochastic differential equations. Several authors $[4,5]$ have investigated RC circuits (both linear and nonlinear) as an electrical representation of the temperature dynamics in a building structure. This paper continuous investigation of thermal models of the buildings and tries developing a framework that can be used by researchers, engineers, and practitioners. The modeling framework shall provide a simple scheme for creating the mathematical model for a building assuming that its geometry and materials properties are known.

\subsection{Organization of the paper}

The paper is organized as follows. In the next section, the modeling assumptions are examined. Section 3 illustrates the modeling concept applied to a single room. Following section applies the concept to an exemplary building structure consisting of five rooms. Section 5 presents the simulation results for a typical situation when the temperature of each room is controlled independently by thermostat units that are mounted on the radiators. Conclusions are in section 6.

\section{Modeling assumptions}

The following assumptions are made when creating the thermal model of a building:

(A1) Indoor air temperature is the same for all points in a room space;

(A2) Density of air is constant throughout all rooms;

(A3) The same amount of air is removed from the building (and each room) as is supplied to it by the ventilation system;

(A4) The geometry of the building and thermal properties of the materials which the building is constructed of are known.

\section{Modeling approach for a single room}

Consider a single room of a building that is enclosed by walls, floor, and ceiling. The room has usually several windows and is accessible via doors. The temperature of the air inside the room with the volume $V_{i}$ is assumed to be uniform and is denoted as $T_{i}$. Denote by $Q_{i}^{\text {in }}$ the thermal power transferred to the room (applied thermal power) and by $Q_{i}^{\text {out }}$ the thermal power transferred out of the room (dissipated thermal power). The relationship in the time domain between the heat that is transferred to or from the room and the temperature of the air inside the room can be expressed by the following equation

$$
\frac{\mathrm{d} T_{i}}{\mathrm{~d} t}=\frac{1}{c \rho V_{i}}\left(Q_{i}^{\text {in }}-Q_{i}^{\text {out }}\right), \quad T_{i}(0)=T_{i}^{0},
$$


where $c$ is the specific heat capacity of air, $\rho$ is the density of air, $T_{i}^{0}$ denotes the initial temperature.

\subsection{Dissipated thermal power}

The overall thermal power loss from a room can be expressed as follows

$$
Q_{i}^{\text {out }}=Q_{i}^{\mathrm{tc}}+Q_{i}^{\mathrm{ve}}
$$

where $Q_{i}^{\text {tc }}$ relates to heat loss by thermal conduction through walls, windows, doors, ceiling, etc., and $Q_{i}^{\mathrm{ve}}$ relates to heat loss by ventilation.

\section{Heat loss by thermal conduction}

The heat loss by thermal conduction can be calculated as (e.g. [15])

$$
Q_{i}^{\mathrm{tc}}=\sum_{j=-1}^{N} A_{i, j} U_{i, j}\left(T_{i}-T_{j}\right),
$$

where $A_{i, j}$ is the area of the exposed surface between $i$-th and $j$-th room, $U_{i, j}$ is the resultant overall heat transfer coefficient that corresponds to $A_{i, j}, N$ is the total number of rooms in the building, the room indexed as $j=-1$ stands for the earth, and $j=0$ stands for the outer space.

The resultant heat transfer coefficient can be calculated as a weighted average of the elements that the surface $A_{i, j}$ is composed of [14], that is

$$
U_{i, j}=\frac{\sum_{k} A_{i, j, k} U_{i, j, k}}{\sum_{k} A_{i, j, k}},
$$

where $\sum_{k} A_{i, j, k}=A_{i, j}$.

\section{Heat loss by ventilation}

The heat loss due to ventilation without heat recovery can be expressed as (e.g., [12])

$$
Q_{i}^{\mathrm{ve}}=c \rho q_{i}\left(T_{i}-T_{0}\right)
$$

where $q_{i}$ denotes air volume flow.

The heat loss due to ventilation with heat recovery can be expressed as

$$
Q_{i}^{\mathrm{ve}}=(1-\beta) c \rho q_{i}\left(T_{i}-T_{0}\right)
$$

where $\beta$ stands for heat recovery efficiency. 


\subsection{Applied thermal power}

The heat gains of the room include the heat from central heating system (radiator heat gain), the heat from solar radiation (solar heat gain), and the heat from occupants, lights, equipment and machinery (internal heat gains):

$$
Q_{i}^{\text {in }}=Q_{i}^{\mathrm{u}}+Q_{i}^{\mathrm{sol}}+Q_{i}^{\mathrm{int}}
$$

\section{Radiator heat gain}

Most central heating systems are based on heated water that is delivered from a central boiler to each room of the house where it transmits the heat to the air through a radiator or some other radiant heating devices. The amount of heat emitted from a radiator can be considered as a regulated parameter in a thermal control system [13]

$$
Q_{i}^{\mathrm{u}}=Q_{i}^{\mathrm{un}}\left(\frac{T_{i}^{\mathrm{uin}}-T_{i}^{\mathrm{uout}}}{T_{\mathrm{c}} \ln \frac{T_{i}^{\mathrm{uin}}-T_{i}}{T_{i}^{\text {uout }}-T_{i}}}\right)^{n},
$$

where $Q_{i}^{\mathrm{u}}$ is the emitted heat, $Q_{i}^{\mathrm{un}}$ is the nominal heat emission specified by the manufacturer, $T_{i}^{\text {uin }}$ is the actual water inlet temperature of the radiator, $T_{i}^{\text {uout }}$ is the actual outlet water temperature from the radiator, $T_{\mathrm{c}}=49.833 \mathrm{~K}$ is the constant temperature difference, $n$ is a constant describing the type of radiator.

\section{Solar heat gain}

When the sun shines through the window, additional heat is transferred into the room (see also [15])

$$
Q_{i}^{\mathrm{sol}}=\sum_{k, j=0} f_{i, j, k}^{\mathrm{c}} f_{i, j, k}^{\mathrm{s}} A_{i, j, k} q_{i, j, k}^{\mathrm{sol}}
$$

where $A_{i, j, k}$ is the area of a window glass, $f_{i, j, k}^{\mathrm{s}}$ is the shading factor, $f_{i, j, k}^{\mathrm{c}}$ is the glass solar factor defined as the percentage of total solar radiant heat energy transmitted through glazing, and $q_{i, j, k}^{\text {sol }}$ is the head load per meter squared window area and this load has been tabulated for various locations, times, dates, and orientations (see e.g., [2]).

\section{Internal heat gains}

Internal heat gains are the gains from occupants, lights, equipment, and machinery. Typical values of internal heat gains can be found in [2]. 


\section{Illustrative example of the thermal model of a house}

Consider a storey house that is set on the ground (Figs. 1 and 2). In the house there are five rooms: a bedroom, a bathroom, a living-room, a kitchen, and an anteroom (Tab. 1). The external walls $(47 \mathrm{~cm})$ of the house are made of four layers including structural clay tile $(30 \mathrm{~cm})$, mineral wool as an insulating material $(15 \mathrm{~cm})$, internal $(1 \mathrm{~cm})$ and external $(1 \mathrm{~cm})$ cement-lime plasters. All internal walls $(12 \mathrm{~cm})$ are made of brick $(10 \mathrm{~cm})$ with $1 \mathrm{~cm}$ cementlime plaster on both sides. The roof is flat and isolated with mineral wool of $20 \mathrm{~cm}$. Steel exterior doors are made out of heave-gauge galvanized steel over a core of rigid foam. All internal doors are made of wood. All windows are double glazed with PVC frames. The building geometry parameters and thermal properties of building construction elements are summarized in the Tables 2-5.

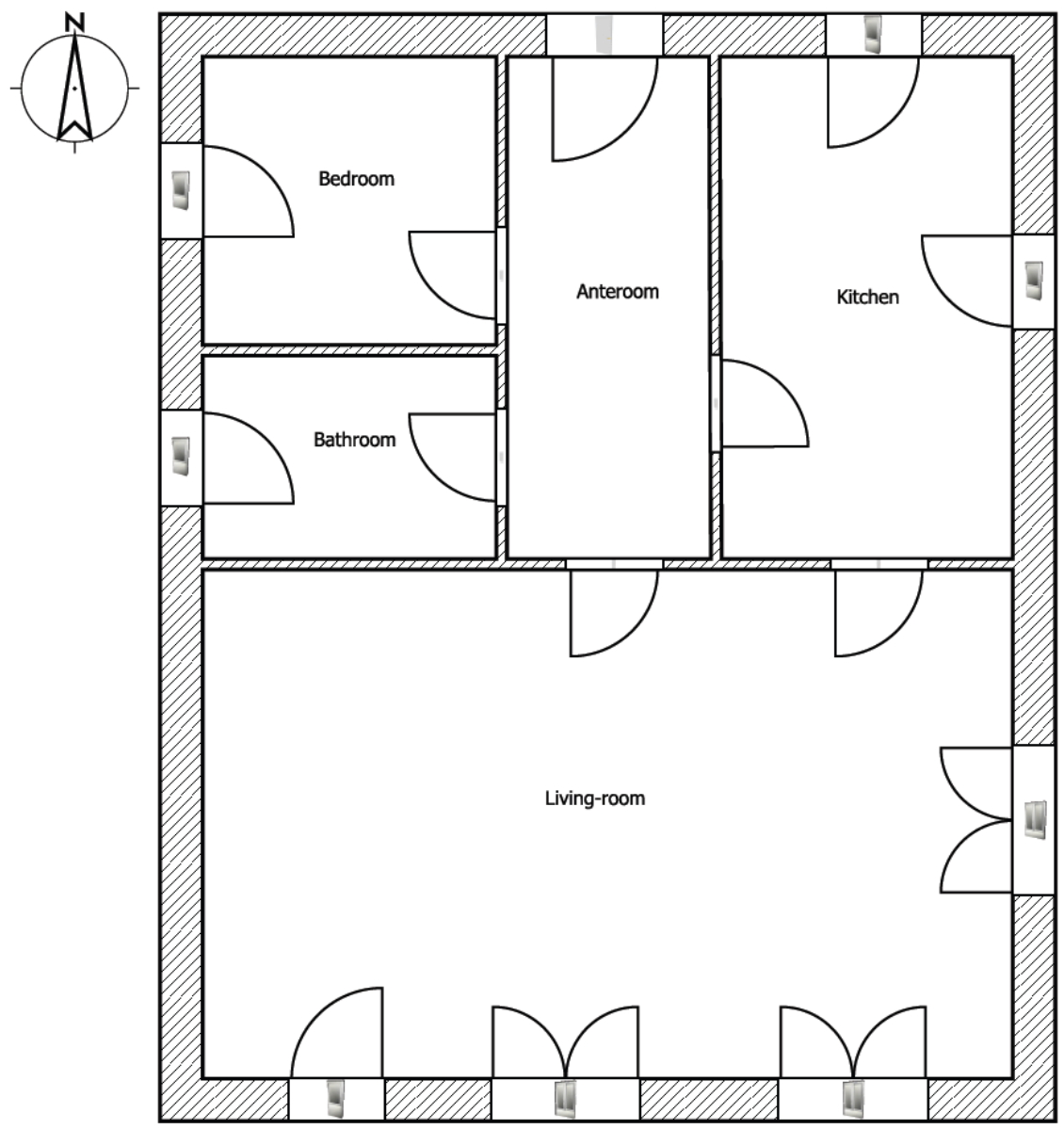

Fig. 1. Floor plan of the house 


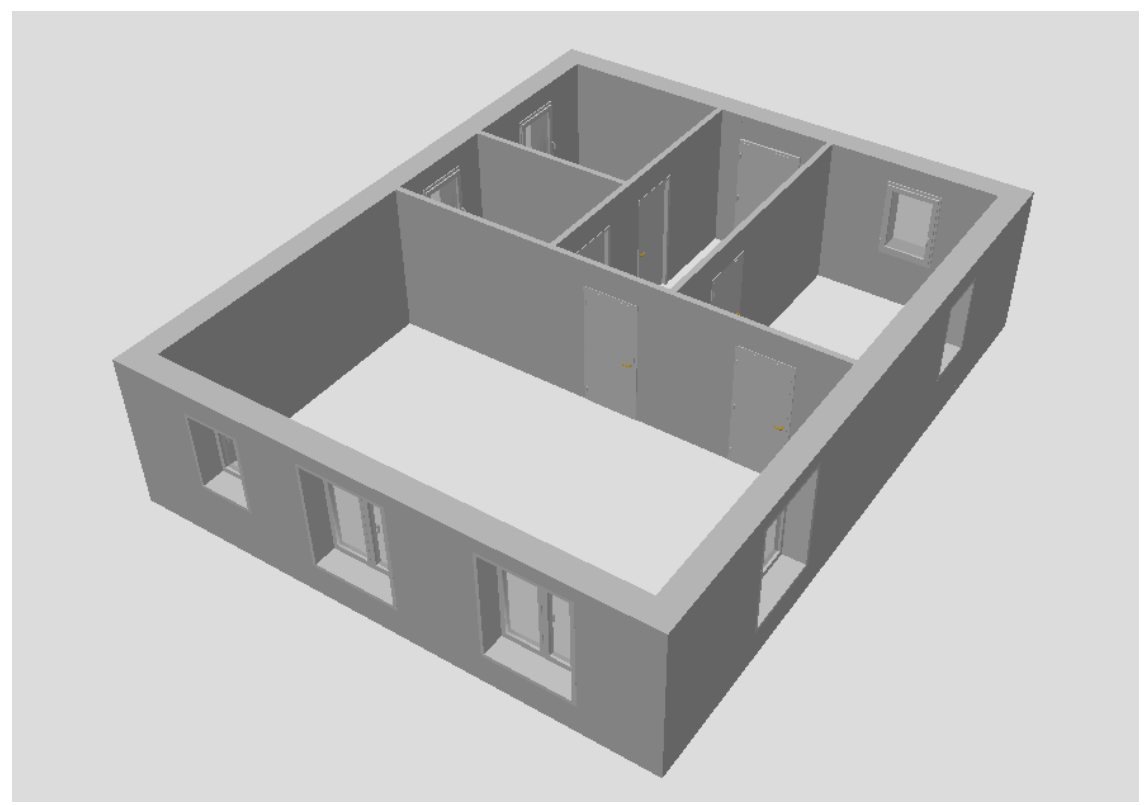

Fig. 2. 3D projection of the house

Table 1

List of rooms with associated indexes. Earth and outer space are also considered as rooms with special indexes: -1 and 0 , respectively

\begin{tabular}{|l|c|}
\hline Room name & Index $i$ \\
\hline Earth & -1 \\
\hline Outer space & 0 \\
\hline Bedroom & 1 \\
\hline Bathroom & 2 \\
\hline Living-room & 3 \\
\hline Kitchen & 4 \\
\hline Anteroom & 5 \\
\hline
\end{tabular}

Table 2

Areas of the surfaces between separated zones

\begin{tabular}{|c|c|c|c|c|c|c|c|}
\hline$A_{i, j}\left[\mathrm{~m}^{2}\right]$ & -1 & 0 & 1 & 2 & 3 & 4 & 5 \\
\hline 1 & 7.51 & 21.18 & 0 & 6.90 & 0 & 0 & 6.77 \\
\hline 2 & 5.31 & 10.11 & 6.90 & 0 & 6.90 & 0 & 4.80 \\
\hline 3 & 36.43 & 79.36 & 0 & 6.90 & 0 & 6.87 & 4.75 \\
\hline 4 & 13.02 & 31.07 & 0 & 0 & 6.87 & 0 & 11.8 \\
\hline 5 & 9.39 & 14.14 & 6.77 & 4.80 & 4.75 & 11.8 & 0 \\
\hline
\end{tabular}


Table 3

Resultant overall heat transfer coefficients corresponding to the surfaces $A_{i, j}$

\begin{tabular}{|c|c|c|c|c|c|c|c|}
\hline$U_{i, j}\left[\mathrm{~W} /\left(\mathrm{m}^{2} \mathrm{~K}\right)\right]$ & -1 & 0 & 1 & 2 & 3 & 4 & 5 \\
\hline 1 & 0.30 & 0.27 & 0 & 0.80 & 0 & 0 & 1.00 \\
\hline 2 & 0.30 & 0.30 & 0.80 & 0 & 0.8 & 0 & 1.08 \\
\hline 3 & 0.30 & 0.30 & 0 & 0.80 & 0 & 0.99 & 1.08 \\
\hline 4 & 0.30 & 0.28 & 0 & 0 & 0.99 & 0 & 0.91 \\
\hline 5 & 0.30 & 0.34 & 1.00 & 1.08 & 1.08 & 0.91 & 0 \\
\hline
\end{tabular}

The house is equipped with a mechanical ventilation and heat recovery system. The air volume flow is assumed to be constant for each room. The heat recovery efficiency is $50 \%$. The parameters of the ventilation system are given in Table 4.

Table 4

Volumes of rooms, ventilation rates, and parameters for calculation of internal heat gains

\begin{tabular}{|c|c|c|c|c|c|}
\cline { 2 - 6 } \multicolumn{1}{c|}{} & 1 & 2 & 3 & 4 & 5 \\
\hline$V_{i}\left[\mathrm{~m}^{3}\right]$ & 18.78 & 13.28 & 91.08 & 32.55 & 23.48 \\
\hline$q_{i}\left[\mathrm{~m}^{3} / \mathrm{h}\right]$ & 20 & 50 & 60 & 70 & 10 \\
\hline$Q_{i}^{\text {intmin }}[\mathrm{W}]$ & 20 & 15 & 25 & 40 & 15 \\
\hline$Q_{i}^{\text {intmax }}[\mathrm{W}]$ & 42.53 & 30.93 & 134.29 & 79.06 & 43.17 \\
\hline
\end{tabular}

Table 5

Other building geometry parameters and thermal properties of building construction elements

\begin{tabular}{|l|c|c|c|}
\hline Parameter & Symbol & Value & Unit \\
\hline Specific heat capacity of air & $c$ & 1005 & $\mathrm{~J} /(\mathrm{kg} \mathrm{K})$ \\
\hline Density of air & $\rho$ & 1.205 & $\mathrm{~kg} / \mathrm{m}^{3}$ \\
\hline Heat recovery efficiency & $\beta$ & 0.5 & - \\
\hline Surface area of exterior doors & $A_{i, j, k}$ & 2.31 & $\mathrm{~m}^{2}$ \\
\hline Surface area of interior doors & $A_{i, j, k}$ & 1.89 & $\mathrm{~m}^{2}$ \\
\hline Surface area of a single window & $A_{i, j, k}$ & 1.17 & $\mathrm{~m}^{2}$ \\
\hline Surface area of a double window & $A_{i, j, k}$ & 2.52 & $\mathrm{~m}^{2}$ \\
\hline Overall heat transfer coefficient of exterior doors & $U_{i, j, k}$ & 0.25 & $\mathrm{~W} /\left(\mathrm{m}^{2} \mathrm{~K}\right)$ \\
\hline Overall heat transfer coefficient of interior doors & $U_{i, j, k}$ & 0.8 & $\mathrm{~W} /\left(\mathrm{m}^{2} \mathrm{~K}\right)$ \\
\hline Overall heat transfer coefficient of a window & $U_{i, j, k}$ & 0.9 & $\mathrm{~W} /\left(\mathrm{m}^{2} \mathrm{~K}\right)$ \\
\hline Shading factors & $f_{i, j, k}^{\mathrm{s}}$ & 0.95 & - \\
\hline Glass solar factors & $f_{i, j, k}^{\mathrm{s}}$ & 0.6 & - \\
\hline Head load for a south-oriented window & $q_{i, j, k}^{\text {sol }}$ & 97 & $\mathrm{~W} / \mathrm{m}^{2}$ \\
\hline Head load for a north-oriented window & $q_{i, j, k}^{\text {sol }}$ & 40 & $\mathrm{~W} / \mathrm{m}^{2}$ \\
\hline Head load for a west-oriented window & $q_{i, j, k}^{\text {sol }}$ & 61 & $\mathrm{~W} / \mathrm{m}^{2}$ \\
\hline Head load for a east-oriented window & $q_{i, j, k}^{\text {sol }}$ & 65 & $\mathrm{~W} / \mathrm{m}^{2}$ \\
\hline
\end{tabular}


The internal heat gains including gains from occupants, lights, equipment, and machinery are modeled using the following formula

$$
Q_{i}^{\text {int }}(t)= \begin{cases}Q_{i}^{\text {intmax }} & \text { between } 6 \text { p.m and } 12 \text { p.m. } \\ Q_{i}^{\text {intmin }} & \text { otherwise }\end{cases}
$$

where the values $Q_{i}^{\text {intmax }}$ and $Q_{i}^{\text {intmin }}$ are given in Table 4 .

The outdoor air temperature is measured using an external sensor. Figure 3 presents a temperature profile that has been used in the simulation experiments. The earth temperature is assume to be stable at the level of $15.0^{\circ} \mathrm{C}$. The sun shines between 8 a.m. and 6 p.m.

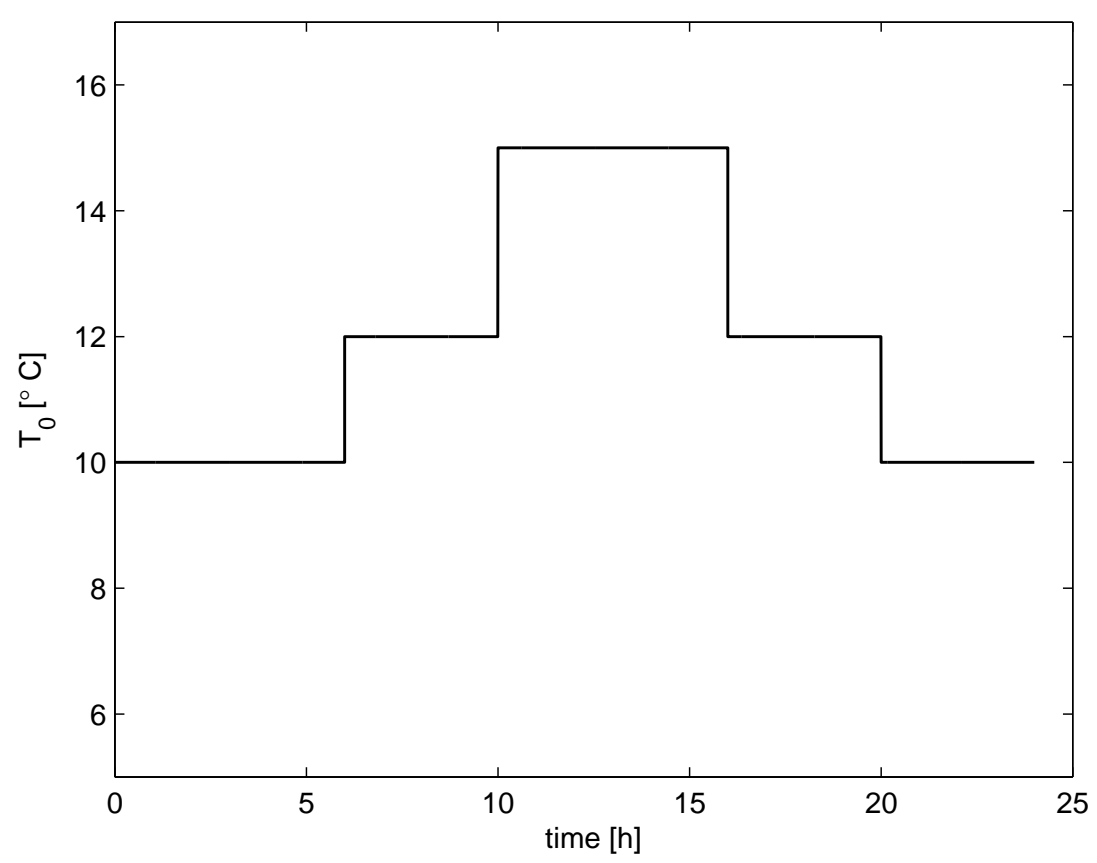

Fig. 3. Outdoor air temperature over the course of the simulation experiment

The dynamics of the indoor air temperature can be now formulated using differential equations of the following form

$$
c \rho \boldsymbol{V} \frac{\mathrm{d} \boldsymbol{T}(t)}{\mathrm{d} t}=\boldsymbol{A} \boldsymbol{T}(t)+\boldsymbol{B} \boldsymbol{u}(t)+\boldsymbol{B}_{0} T_{0}(t)+\boldsymbol{B}_{-1} T_{-1}(t)+\boldsymbol{Q}^{\mathrm{int}}(t)+\boldsymbol{Q}^{\mathrm{sol}}(t),
$$

where $\boldsymbol{T}(t)=\operatorname{col}\left(T_{1}(t), T_{2}(t), \ldots, T_{5}(t)\right), \boldsymbol{u}(t)=\operatorname{col}\left(u_{1}(t), u_{2}(t), \ldots, u_{5}(t)\right), u_{i}(t)=Q_{i}^{\mathrm{u}}(t)$ for $i=1,2, \ldots, 5, \boldsymbol{V}=\operatorname{diag}\left(V_{1}, V_{2}, \ldots, V_{5}\right)$, 


$$
\begin{gathered}
\boldsymbol{A}=\left[\begin{array}{cccc}
-\sum_{j=1}^{5} A_{1, j} U_{1, j} & A_{1,2} U_{1,2} & \ldots & A_{1,5} U_{1,5} \\
A_{2,1} U_{2,1} & -\sum_{j=1}^{5} A_{2, j} U_{2, j} & \ldots & A_{2,5} U_{2,5} \\
\vdots & \vdots & \ddots & \vdots \\
A_{5,1} U_{5,1} & A_{5,2} U_{5,2} & \ldots & -\sum_{j=1}^{5} A_{5, j} U_{5, j}
\end{array}\right]-(1-\beta) c \rho\left[\begin{array}{c}
q_{1} \\
q_{2} \\
\vdots \\
q_{5}
\end{array}\right] \boldsymbol{I}, \\
\boldsymbol{B}=I, \quad \boldsymbol{B}_{-1}=\left[\begin{array}{c}
A_{1,-1} U_{1,-1} \\
A_{2,-1} U_{2,-1} \\
\vdots \\
A_{5,-1} U_{5,-1}
\end{array}\right], \quad \boldsymbol{B}_{0}=\left[\begin{array}{c}
(1-\beta) c \rho q_{1}+A_{1,0} U_{1,0} \\
(1-\beta) c \rho q_{2}+A_{2,0} U_{2,0} \\
\vdots \\
(1-\beta) c \rho q_{5}+A_{5,0} U_{5,0}
\end{array}\right] \\
\boldsymbol{Q}^{\text {sol }}(t)=\left[\begin{array}{c}
Q_{1}^{\text {int }}(t) \\
Q_{2}^{\text {int }}(t) \\
\vdots \\
q_{1,0,1}^{\text {sol }}(t) f_{1,0,1}^{\mathrm{c}}(t) f_{2,0,1}^{\mathrm{c}} f_{2,0,1}^{\mathrm{s}} A_{2,0,1} A_{1,0,1} \\
\sum_{k=1}^{4} q_{3,0, k}^{\text {sol }}(t) f_{3,0, k}^{\mathrm{c}} f_{3,0, k}^{\mathrm{s}} A_{3,0, k} \\
\sum_{k=1}^{2} q_{4,0, k}^{\text {sol }}(t) f_{4,0, k}^{\mathrm{c}} f_{4,0, k}^{\mathrm{s}} A_{4,0, k} \\
0
\end{array}\right], \quad \boldsymbol{Q}^{\text {int }}(t)=\left[\begin{array}{c}
\text { int }(t)
\end{array}\right]
\end{gathered}
$$

$t>0$, the initial condition $\boldsymbol{T}(0)=\left[\begin{array}{lll}17.0 & 18.020 .0 & 19.016 .0\end{array}\right]^{\mathrm{T}}{ }^{\circ} \mathrm{C}$ is given.

\section{Illustrative example of the control algorithm design}

The house is equipped with a central heating system and each room has its own radiator. A thermostat unit is mounted on each radiator and all radiators in the house work independently. This is a very typical control scheme for most of the buildings. The thermostat controls the flow of hot, central heating water, into the radiator. In the simulation experiments it is assumed that the thermostat implements PID control algorithm that is

$$
u_{i}(t)=K\left(e_{i}(t)+\frac{1}{T_{\mathrm{i}}} \int_{0}^{t} e_{i}(\tau) \mathrm{d} \tau+T_{\mathrm{d}} \frac{\mathrm{d} e_{i}(t)}{\mathrm{d} t}\right), \quad e_{i}(t)=T_{i}^{\mathrm{set}}-T_{i}(t),
$$

where $K=50$ is proportional gain, $T_{\mathrm{i}}=1000 \mathrm{~s}$ is integral time, $T_{\mathrm{d}}=0.0025 \mathrm{~s}$ is derivative time, $T_{i}^{\text {set }}=21^{\circ} \mathrm{C}, i=1,2, \ldots, 5$ are the desired set temperatures. The following constraints imposed by the radiator construction are valid for $t>0$

$$
\begin{aligned}
& 0 \mathrm{~W} \leq u_{i}(t) \leq 500 \mathrm{~W}, \\
& 0 \mathrm{~W} \leq u_{i}(t) \leq 500 \mathrm{~W}, \\
& 0 \mathrm{~W} \leq u_{i}(t) \leq 3000 \mathrm{~W}, \\
& 0 \mathrm{~W} \leq u_{i}(t) \leq 800 \mathrm{~W}, \\
& 0 \mathrm{~W} \leq u_{i}(t) \leq 400 \mathrm{~W}
\end{aligned}
$$


The simulation results are presented in Figures 4-8. The total energy needed to heat the house during a simulated day (a day has 24 hours) is equal to $9.26 \mathrm{kWh}$.

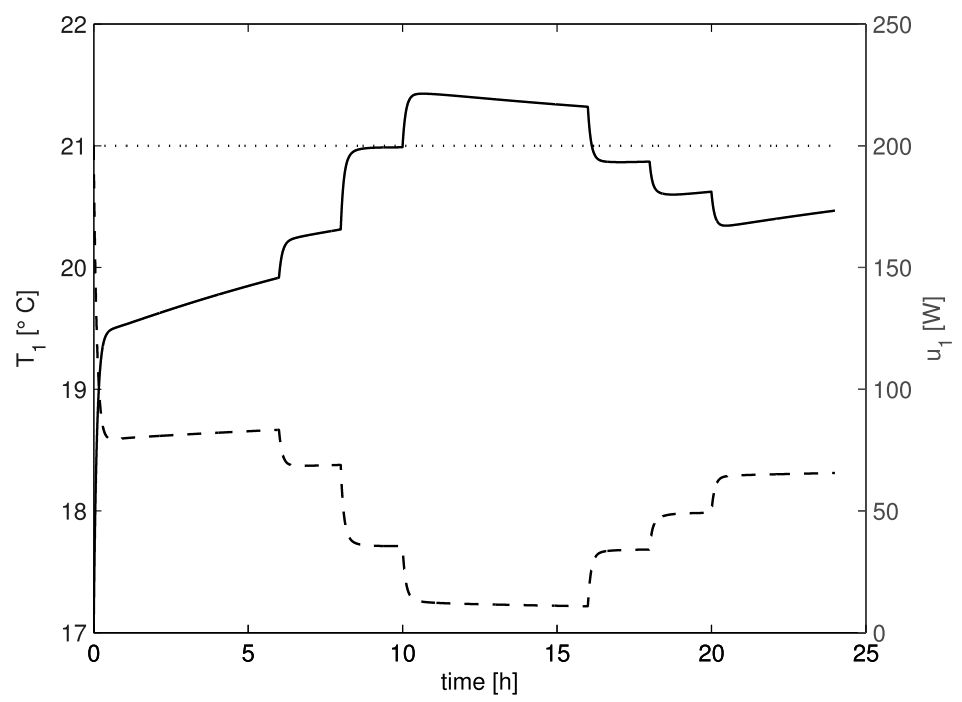

Fig. 4. Temperature $T_{1}$ in the bedroom (solid line) and radiator power (dashed line) applied by the thermostat unit that has been programmed to keep the indoor temperature at the set level (dotted line)

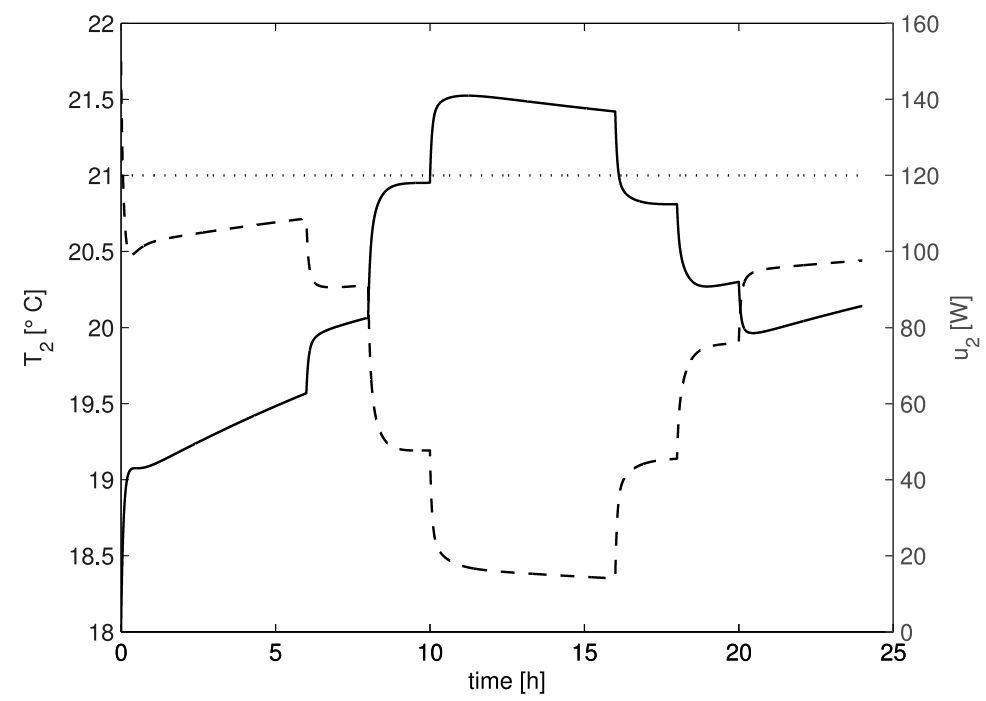

Fig. 5. Temperature $T_{2}$ in the bathroom (solid line) and radiator power (dashed line) applied by the thermostat unit that has been programmed to keep the indoor temperature at the set level (dotted line) 


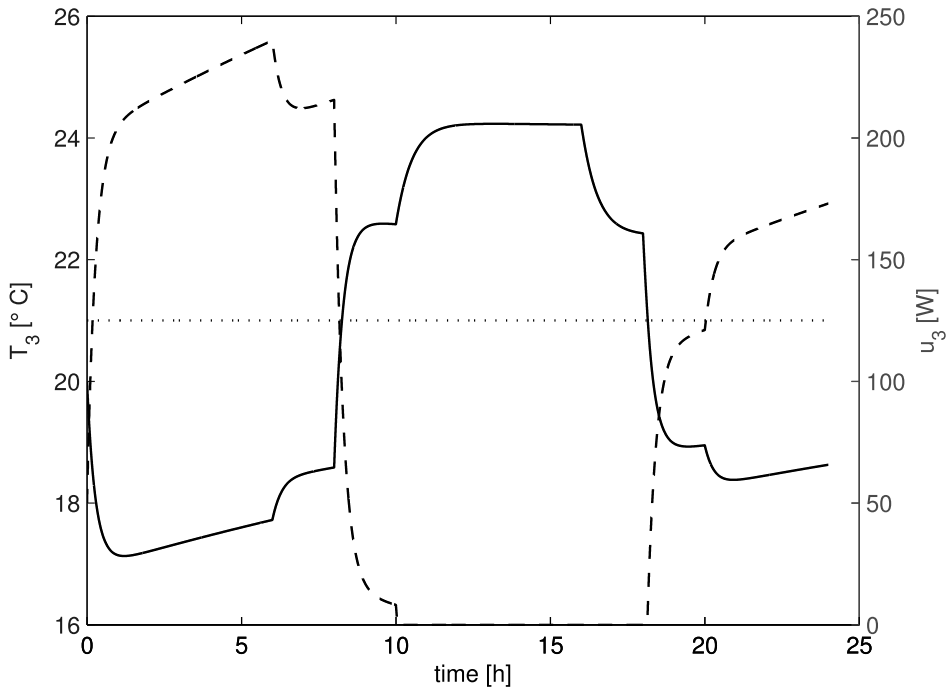

Fig. 6. Temperature $T_{3}$ in the living-room (solid line) and radiator power (dashed line) applied by the thermostat unit that has been programmed to keep the indoor temperature at the set level (dotted line)

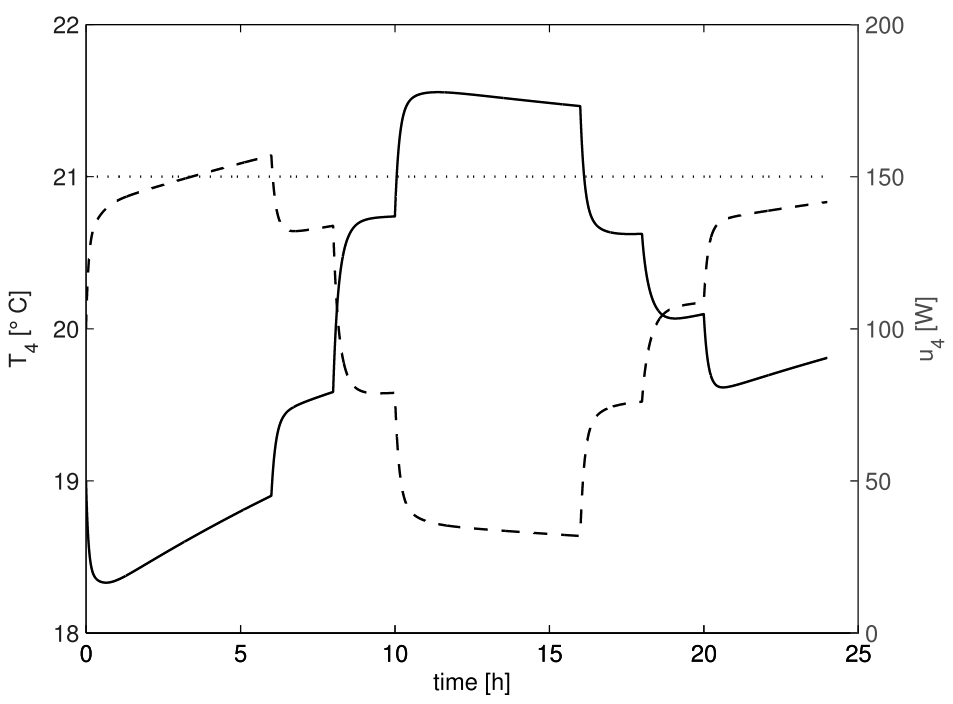

Fig. 7. Temperature $T_{4}$ in the kitchen (solid line) and radiator power (dashed line) applied by the thermostat unit that has been programmed to keep the indoor temperature at the set level (dotted line) 


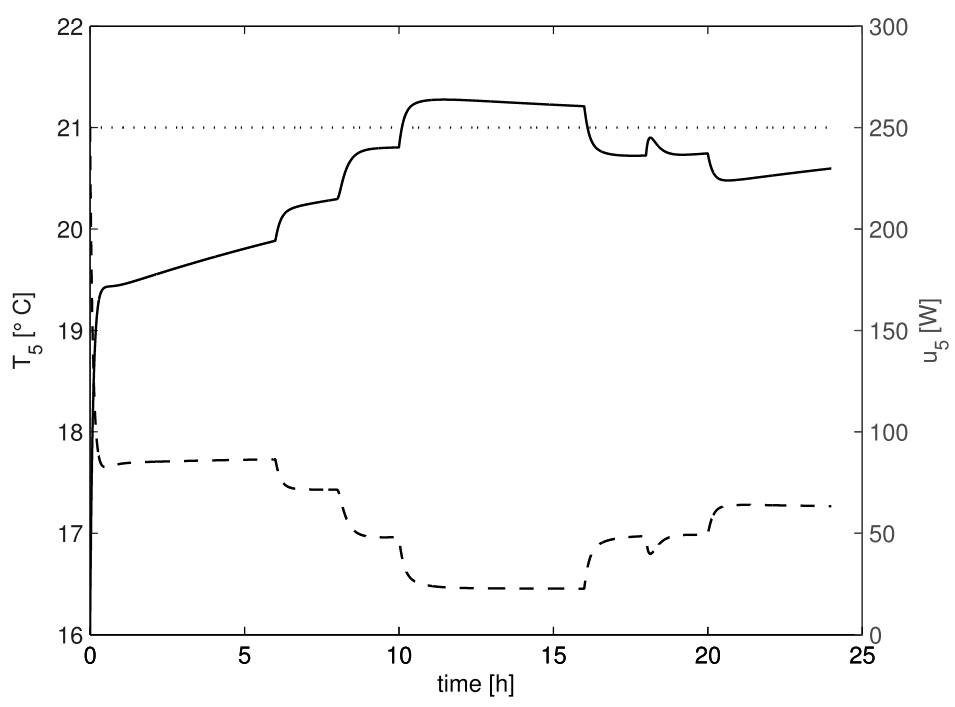

Fig. 8. Temperature $T_{5}$ in the anteroom (solid line) and radiator power (dashed line) applied by the thermostat unit that has been programmed to keep the indoor temperature at the set level (dotted line)

\section{Conclusions}

This paper has described an efficient and practical way for modeling heat transfer dynamics in a building which can be an office area, apartment house, industrial plant, etc. The resulted mathematical model is represented by first order differential equations. The number of rooms where the indoor air temperature shall be controlled determines the order of the dynamical model. The modeling approach allows incorporating of various form of heat loses and various forms of heat gains. One of the main advantages of the presented approach is that the model parameters can be determined easily and uniquely from the geometry of the building and thermal properties of the building materials. As a result, formal identification of the model parameters is not required. The approach leads to mathematical models that can be used for the design of the temperature control algorithms as well as for the calculation of the overall energy consumption.

\section{Acknowledgements}

This work was supported by the National Science Centre (Poland) -project No N N514 644440. 


\section{References}

[1] Andersen K., Madsen H., Hansen L., Modelling the heat dynamics of a building using stochastic differential equations. Energy and Buildings, 31(1):13-24, 2000.

[2] CIBSE, Guide A: Environmental design, 2006. https://www.cibseknowledgeportal.co.uk. Accessed 29 August 2012.

[3] Fourier J., The Analytical Theory of Heat. Dover Publicatons, Inc., New York, USA, 1955.

[4] Gouda M., Danaher S., Underwood C., Low-order model for the simulation of a building and its heating system. Building Services Engineering Research and Technology, 21(3):199-208, 2000.

[5] Gouda M., Danaher S., Underwood C., Building thermal model reduction using nonlinear constrained optimization. Building and Environment, 37(12):1255-1265, 2002.

[6] Jakob M., Heat Transfer. John Willey \& Sons, New York, USA, 1949.

[7] Lienhard IV J.H., Lienhard V J.H., A Heat Transfer Textbook. 3rd Edition. Phlogiston Press, Cambrige, Massachusetts, USA, 2008.

[8] Lu X., Modelling of heat and moisture transfer in buildings: I. model program. Energy and Buildings, 34(10):1033-1044, 2002.

[9] Lu X., Clements-Croome D., Viljanen M., Past, present and future mathematical models for buildings: focus on intelligent buildings (part 1). Intelligent Buildings International, 1(1):23-38, 2009.

[10] Lu X., Clements-Croome D., Viljanen M., Past, present and future mathematical models for buildings: focus on intelligent buildings (part 2). Intelligent Buildings International, 1(2):131141, 2009b.

[11] McAdams W., Heat Transmission. 3rd ed. McGraw-Hill Book Company, New York, USA, 1954.

[12] Polish Committee for Standardization, PN-B-03430:1983. Ventilation in dwelling and public utility buildings - Specifications, 1983. http://www.pkn.pl. Accessed 29 August 2012.

[13] Polish Committee for Standardization, PN-EN 442-1:1999. Radiators and convectors - Technical specifications and requirements, 1999. http://www.pkn.pl. Accessed 29 August 2012.

[14] Polish Committee for Standardization, PN-EN ISO 6946:2008. Building components and building elements. Thermal resistance and thermal transmittance - Calculation method, 2008. http://www.pkn.pl. Accessed 29 August 2012.

[15] Polish Committee for Standardization, PN-EN ISO 13790:2009. Thermal performance of buildings - Calculation of energy use for space heating and cooling, 2009. http://www.pkn.pl. Accessed 29 August 2012.

[16] Poulikakos D., Conduction Heat Transfer. Prentice-Hall, Englewood Cliffs, New York, USA, 1994. 